\title{
Improved rack and pinion drive
}

\author{
Tadeusz Sawicki \\ presmet@presmet.com.pl | (D) https://orcid.org/0000-0002-1797-4464 \\ APC Presmet Sp. z o.o., Opole
}

Scientific Editor: Stanistaw Mtynarski, Cracow University of Technology Technical Editor: Aleksandra Urzędowska, Cracow University of Technology Press Language Verification: Timothy Churcher, Merlin Language Services Typesetting: Anna Basista, Cracow University of Technology Press

Received: January 22, 2021

Accepted: August 30, 2021

Copyright: ๑ 2021 Sawicki, This is an open access article distributed under the terms of the Creative Commons Attribution License, which permits unrestricted use, distribution, and reproduction in any medium, provided the original author and source are credited.

Data Availability Statement: All relevant data are within the paper and its Supporting Information files.

Competing interests: The authors have declared that no competing interests exist.

\begin{abstract}
A typical rack and pinion drive set is comprised of a rack and a pinion. There is an inter-tooth clearance between the mating teeth of the rack and the pinion, which has advantages and disadvantages. The disadvantage of this clearance is the errors that occur in the positioning of the machine tool during set-up. Elimination of clearance between teeth is possible by using a pinion drive with two pinions. This ensures continuous contact between the teeth, regardless of the direction of machine movement.

These are found on new machines, while older machines do not have such a solution. This paper presents a solution with two pinions, which can be used in such older machines and which makes it possible to achieve qualitative parameters that were not possible before.
\end{abstract}




\section{Introduction}

The rack-and-pinion drive has been used from many years in large cutting machines, such as drilling and milling machines, as well as in the rotary tables that these machines are equipped with.

The classic rack and pinion drive is shown in Fig. 1 and consists of the following components: electric motor, gearbox, pinion wheel and rack. The gearbox and rack are open gears and their contact teeth are drip lubricated with oil. Lengths of the toothed slats can reach even several dozen meters. Due to this design and lubrication, the teeth of rack and pinion drives are made with a clearance referred to as the clearance between teeth, the size of which depends on the module of teeth.

For example, for the $6 \mathrm{~mm}$ module, this play varies within the range from 0.17 to $0.388 \mathrm{~mm}$, with

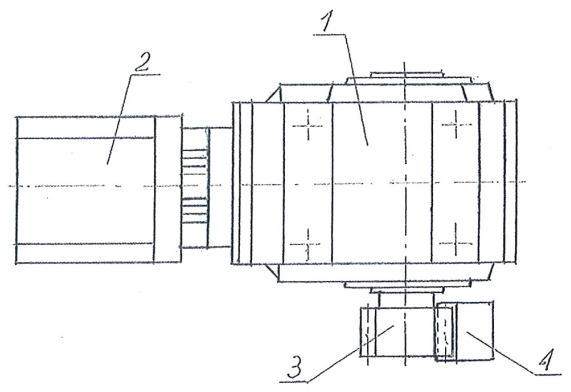
an average value of $0.254 \mathrm{~mm}$. The advantage of the clearance between the teeth is the correct interlocking of the contact teeth during operation, while the disadvantages are positioning errors of the machine tool. These errors are particularly noticeable when milling profiles with closed shapes such as circles, rectangles or squares.

The clearance between the teeth increases during operation of the machine tool as a result of wear and tear of the cooperating teeth.

\section{Eliminating the impact of clearance between teeth}

The clearance between teeth as defined is the shortest distance between two neighboring non-contacting teeth when one of these teeth is in contact with another tooth (Ochęduszko, 1985). This distance between the non-working sides of the teeth is a blind spot, which is overcome by the pinion each time the machine changes direction.

The size of the clearance between the teeth at significant magnification is shown in Fig. 2. On numerically controlled machine tools, each passage through the blind spot leads

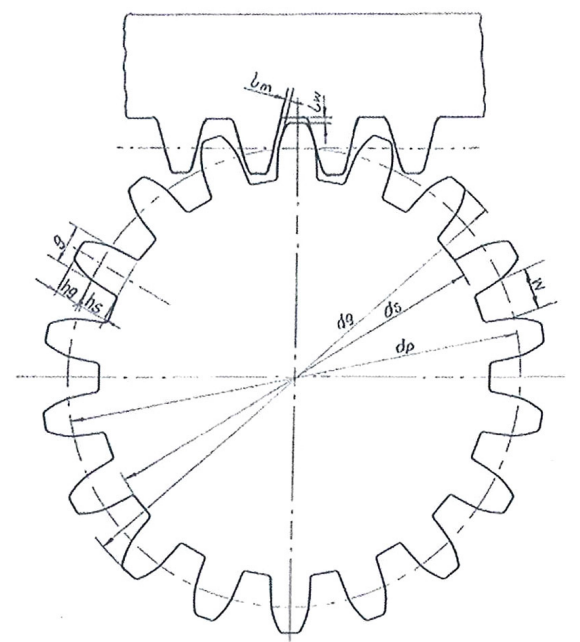

Fig. 1. The classic rack and pinion drive: 1 - gearbox, 2 - electric motor, 3 - pinion wheel, 4 - toothed bar
Fig. 2. Main gearing sizes: 1 - rack and pinion, 2 - pinion, $L_{m}$ - clearance between teeth, $l_{w}$ - appex slack, $d_{p}$ - pitch diameter,

$d_{s}$ - diameter of the head of the teeth, $d$ - diameter of teeth feet, $g$ - tooth thickness on the pitch diameter, $h_{s}$ - tooth head height, $h_{s}$ - tooth foot height, $w$ - the width of the inter-tooth rebate to incorrect computer readings, as the drive is moving while the machine remains motionless.

When the pinion passes through the blind spot and has continuous contact with the linear gear (the rack), the indications of movement of the machine tool are correct and not affected by error. Therefore, it is necessary to find such a constructional solution of rack and pinion drive that the teeth of the pinion and the rack are in constant contact with each other in both directions of movement. This was only possible with the introduction of a second pinion. A schematic representation of this solution is shown in Fig. 3.

The two pinions work closely together. The principle of operation of such a set is as follows: the first fixed pinion

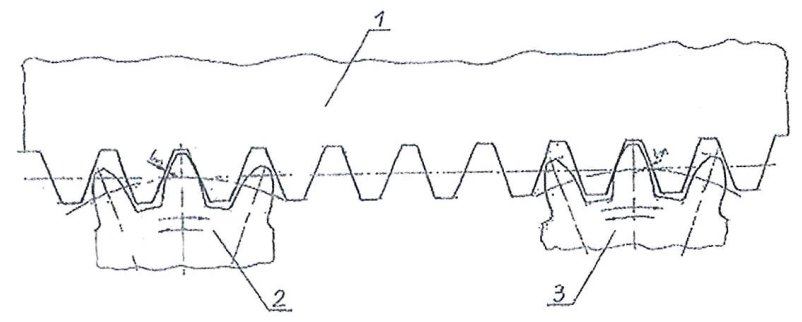

Fig. 3. Two pinion drive: 1 - rack and pinion, 2 - first fixed tooth, 3 - second movable tooth 


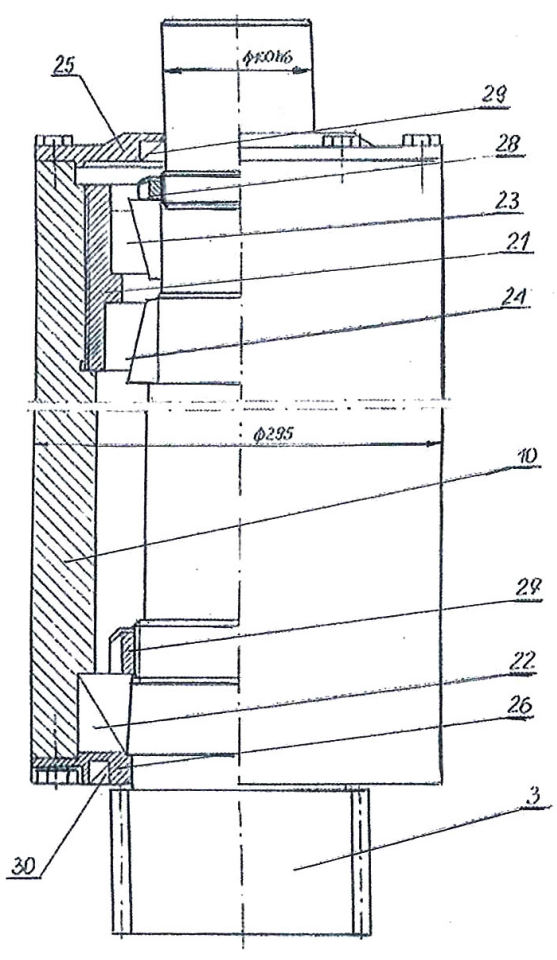

Fig. 4. Second pinion housing: 3 - second pinion, 10 - housing body, 21 - addition bearing sleeve, 22 - double row cylindrical roller bearing with inner tapered bushing, 23 and 24 tapered roller bearings, 25 and 26 - lids, 27 and 28 - bearing nuts, 29 and 30 - seals contacts the rack teeth while moving in one direction, the second movable pinion is tightened to the rack teeth by contacting them from the other side and ensures clearance, i.e. free movement of the machine in the other direction.

This two-pinion drive design completely eliminates harmful clearance between teeth. Two pinion rack and pinion drives are used by various world companies in their new products. Companies report that their devices achieve good results in positioning; this applies to:

- Union Werkzeugmaschinen GmbH Chemnitz in machine tools;

- Kuraki Co., Ltd., Japan, on rotary tables;

- Shang Hui Machinery Design Co., also on rotary tables.

\section{Construction of an improved rack and pinion drive}

\subsection{Background}

Manufacturers of new two-tooth drive equipment have been designing such a solution from the very beginning.

At present, there remain a lot of drilling and milling machines produced in the nineteen-seventies and nineteen-eighties that do not have a rack and pinion drive. The incorporation of a two pinion drive into such machine tools poses major problems, however, these can be solved.

The improved rack and pinion drive presented in this study relates to a specific case, which is the "SKODA" type WD200B drilling and milling machine, which was constructed in 1972, retrofitted with a numerical control mechanism.

The main drive of the first pinion is equipped with a new generation clearance - free gear with a small slip angle between the input and output shaft. The sides of the body of such a gearbox are accurately machined. On these sides, there are holes for fixing other elements. The holes are carefully arranged relative to the main axis of the drive. One of these machined sides of the main gear was used to set up and fix the body with the other pinion. The basic conditions for proper functioning of both pinions in the drive are:

- precise dimensional execution of both pinions;

- clearance-free rotation in both pinions simultaneously;

- correct positioning of both pinions in relation to each other and to the main axis of the gears.

The improved rack and pinion drive concerns both angled teeth and the $6 \mathrm{~mm}$ module. The entire design solution of the improved rack and pinion drive has been filed as an invention with the Patent Office of the Republic of Poland and registered under number P.431714 on 2019-11-05.

\subsection{Second pinion in housing}

Both pinions are made from a rod with a diameter of $200 \mathrm{~mm}$ and a length of about $1210 \mathrm{~mm}$. The rod was made of a material suitable for carburizing and subsequent heat treatment. Each pinion has the normal module of $6 \mathrm{~mm}$ and 29 oblique teeth turned to the left. After manufacturing, the first pinion was mounted directly in the main drive gear. The second pinion was mounted in a casing, which took the form of a thick-walled pipe of the following dimensions after machining: external diameter $295 \mathrm{~mm}$, length $957 \mathrm{~mm}$.

Inside the housing there are sockets for pinion bearings. The total length of the pinion after machining was $1200 \mathrm{~mm}$. The end of the rod opposing the pinion, used for drive transmission, has a diameter of $100 \mathrm{~mm}$ with a tolerance of h6. The second pinion in the casing is shown in Fig. 4.

The item numbering shown in this figure is the same as that shown in the overview drawing of the entire two pinion drive. 


\subsection{Fixing and positioning the second pinion housing}

The second pinion, which is mounted in the casing, needs to be precisely fixed and aligned to the first pinion. One machined side of the main gearbox is used for this purpose. The structure for fixing the second casing to the main gearbox is shown in Fig. 5. This construction consists of the following elements: load-bearing plate (item 14), casing clamp consisting of two parts (items 15 and 16) and two hydraulic cylinders (item 8).

The setting and fixing of the carrier plate (item 14) in relation to the main axis of the gearbox is shown in Fig. 6. After setting and screwing it in, the plate is locked with the locking pins.

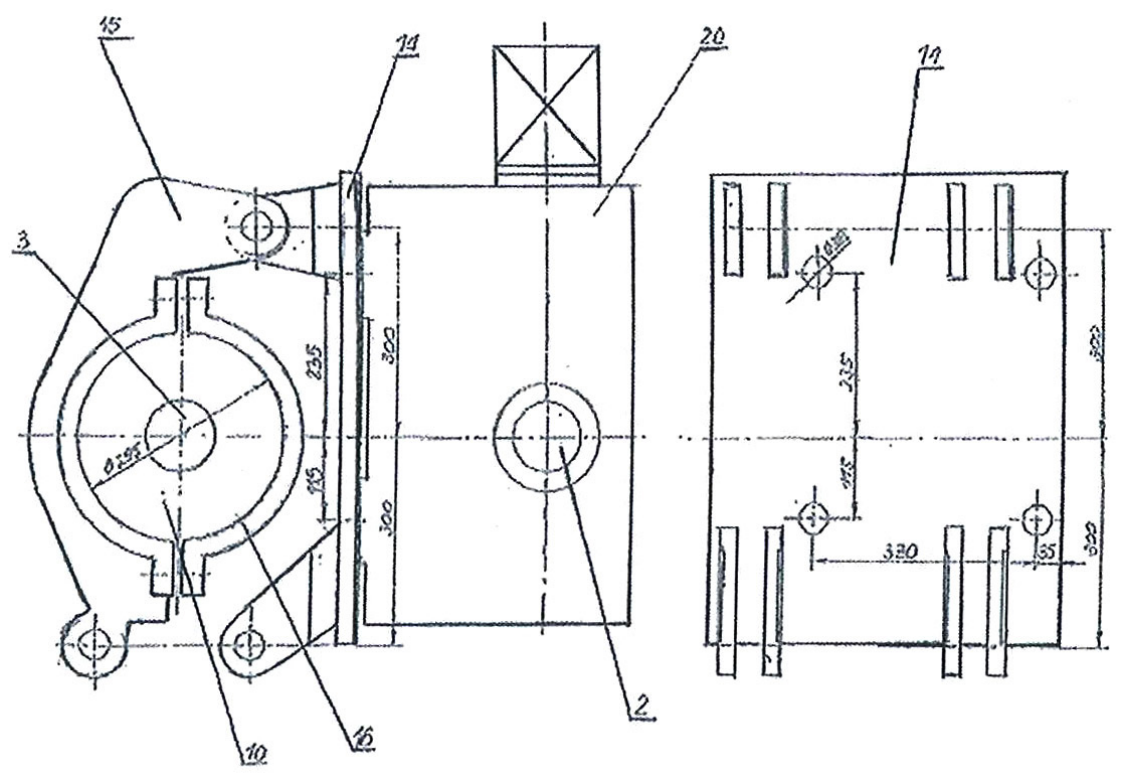

Fig. 5. Clamping structure of the second pinion housing, 10 - housing body, 14 - backing plate, 15 and 16 - clamp, 20 - main gearbox

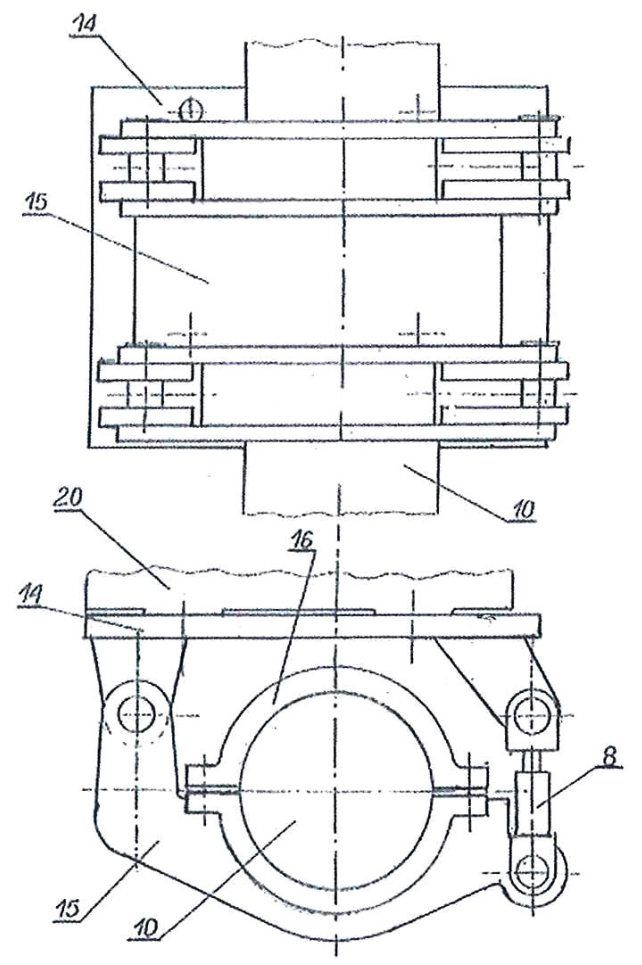

Fig. 6. Setting and fixing the second pinion to the main gear: 2 - first pinion, 3 - second pinion, 10 - housing body, 14 - backing plate, 15 and 16 - clamp, 20 - main gearbox

\subsection{Secondary pinion drive}

The drive of the second pinion is highly dependent on the drive of the first pinion.

Both of these drives must meet the following conditions:

1) they must have the same number of revolutions per unit time,

2) they must always turn in the same direction,

3 ) the rotation of the second pinion relative to the first must not be affected by any slippage. The design of the second pinion drive is shown in Fig. 7. The second pinion receives drive from the first pinion. These are the conditions that both sprockets must satisfy when providing a chain transmission.

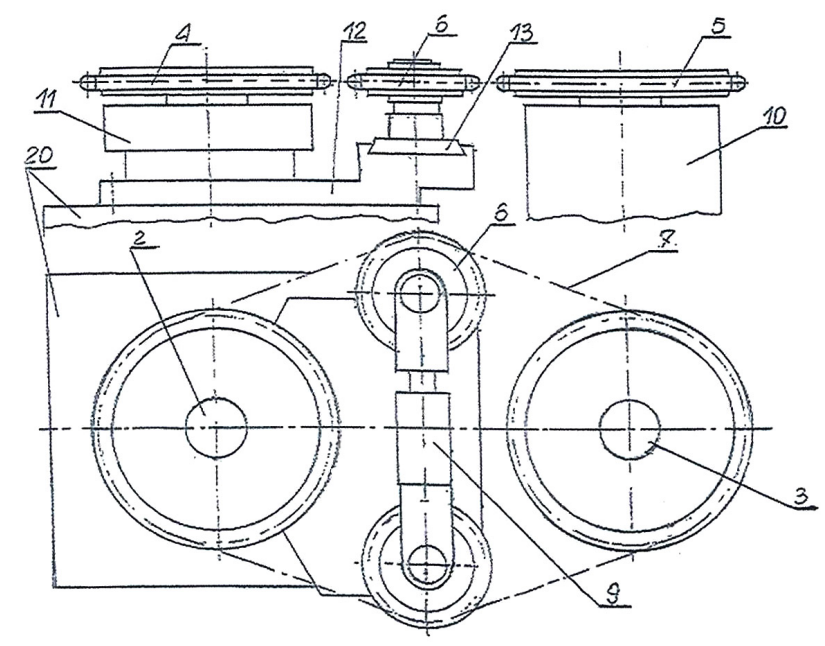

Fig. 7. Secondary pinion drive: 2 - fixed pinion in the gearbox, 3 - second pinion in housing, 4 - sprocket fitted to sprocket item 2 , 5 - chain wheel mounted on sprocket pos. 3, 6 - chain tension sprockets pcs. 2, 7 - Galla bolt chain 1,5 inch, 9 - chain tension actuator, 10 - housing for second pinion pos. 3 , 11 - housing for additional fixed pinion bearing pos. 2, 12 - chain tensioning guide body, 13 - chain tensioning sprocket guides, 20 - main gearbox 


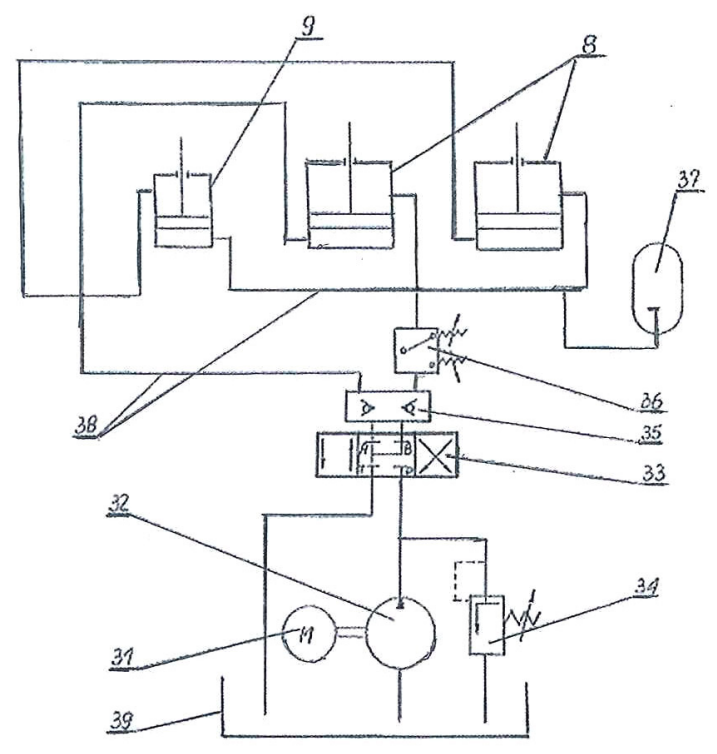

This gearbox consists of two identical sprockets which are clamped at the ends of sprockets of diameter $100 \mathrm{~h} 6$ (items 4 and 5), and two sprockets (item 6).

All these sprockets are wrapped around the chain (item 7), which is respectively tensioned by the wheels (item 6 ) and the hydraulic cylinder (item 9). Sprockets (item 6) mounted in the housing (items 12 and 13) are movable for chain tension.

In the body of pos. 11 there is an additional bearing of the tip of the first pinion (item 2), in order to ensure its proper rigidity. By strapping the sprockets of items 4 and 5 with a chain which is sufficiently taut and with a strapping angle of almost 180 degrees, the three conditions for the proper functioning of the drive of both sprockets can be met.

\subsection{Contact of the teeth of the second pinion with the teeth of the rack}

An important issue in this design of a two-gear drive is to ensure adequate pressure between the contacting teeth. The second pinion is designed to be able to adjust its position for proper tooth meshing during operation.

Fig. 8. Diagram of the hydraulic system fot the second pinion: 8 - pinion clamping cylinders, 9 - chain tension actuator, 31 - electric motor, 32 - gear oil pump, 33 - manifold, 34 - bypass valve, 35 - controlled double check valve, 36 - pressure transmitter, 37 - hydeaulic accumulator, 38 - hydraulic hoses, 39 - oil tank

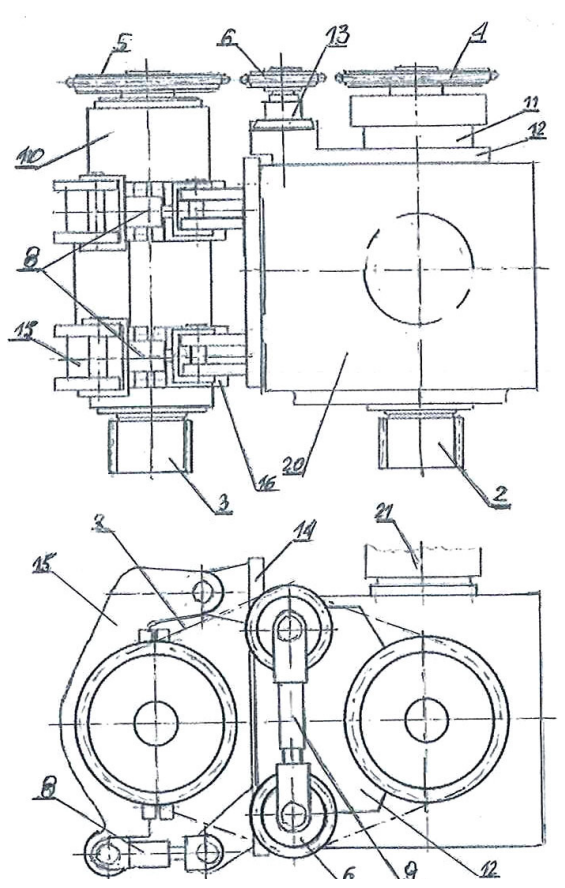

Fig. 9. Overview drawing of two pinion drive: 2 - fixed pinion in the gearbox, 3 - second pinion in housing, 4 - sprocket wheel on fixed sprocket, 5 - sprocket driven on second sprocket, 6 - tensioning sprockets, 7 - pin chain, 8 - clamping cylinder, 9 - chaintension actuator 10 - housing for second pinion, 11 - housing for additional fixed pinion bearing,

12 - chaintensioning guide body, 13 - chain tensioning sprocket guides, 14 - second pinion mounting plate with gear, 15 - fixed bracket for thehousing of the second pinion, 20 - bevel gearbox, 21 - servo motor
The pressure of the mating teeth of the second pinion on the teeth of the toothed rack must ensure that the cutting resistance and the resistance resulting from the movement of the machine along the bed guideways are overcome. The clamping required for the correct operation of the second pinion in the machine tool is made by a hydraulic system. A diagram of such a hydraulic system is presented in Fig. 8.

The main components of this system are two direct tine clamping actuators (item 8) and the chain tension actuator of the drive sprocket (item 9). The size of the cylinders and the prevailing oil pressure depends on the size of the force on the pitch diameter of the first pinion.

The calculated value of this force is:

where:

$$
p=\frac{2 M_{o}}{d_{p}}
$$

$M_{\circ}$ - rated torque of main drive gearbox

$d_{p}^{o}$ - pitch diameter of a gear or pinion

The calculated force value will determine the size of the actuators and the optimum oil pressure.

The small hydraulic power pack installed on the machine moves with the machine. Constant oil pressure in the system is maintained by the hydraulic accumulator installed in the unit.

\subsection{Combination of the entire drive with two pinions}

The twin pinion drive design is compact and can be fitted to a machine tool. The components of this mechanism are shown in Fig. 9.

The subassemblies and their parts including the hydraulic cylinders, were manufactured on standard machine tools.

\section{Results and Discussion}

In order to confirm the improved positioning precision of the two pinion design applied to the "SKODA" type WD 200B milling machine, measurements of the accuracy of positioning in the horizontal axis " $X$ " were conducted before and after modernisation. The horizontal working travel of this machine is $10,600 \mathrm{~mm}$.

Measurements were performed with a Renishaw XL-10 laser interferometer with the following parameters: measurement resolution $0.01 \mu \mathrm{m}$, measurement accuracy $0.1 \mu \mathrm{m}(1 \mu \mathrm{m}=0.001 \mathrm{~mm})$. 
The measurement was made over the entire working travel distance in both directions in $200 \mathrm{~mm}$ steps. The measuring instrument connected to the computer determined the positioning deviation graph.

The first measurement was peformed on $15^{\text {th }}$ January 2008, when the machine tool drive did not have a set with two pinions. A graph of positioning errors is shown in Fig. 10. The diagram shows the following errors: max. $300 \mu \mathrm{m}$ in the positive direction, max. $400 \mu \mathrm{m}$ in the negative direction. Overall, the total positioning error was $700 \mu \mathrm{m}$ which is a significant error.

The second measurement was performed with the same measuring instrument on $20^{\text {th }}$ June 2011, after equipping the machine with a drive set with two pinions. A plot of the positioning errors over the same measuring section is shown in Fig. 11. From this graph, it can be seen that the maximum positioning error in both directions is $\pm 0.1 \mathrm{~mm}$, for a total of $0.2 \mathrm{~mm}$.

Comparing these results with the results of the first measurement, there is a clear improvement in positioning. This improvement is due to the second pinion in the drive. A third measurement of the positioning accuracy was performed on $18^{\text {th }}$ December 2019, also with the same measuring instrument according to ISO-230. A graph of the positioning deviations from this measurement is shown in Fig. 12.

The ISO-230 standard requires three measurements in each direction, which is why this graph is so elaborate.

This graph shows that despite having been in operation for around 8 years, the machine has small positioning deviations of $\pm 200 \mu \mathrm{m}$ over the measuring range from $0 \mathrm{~mm}$ to around $9000 \mathrm{~mm}$. Worse results are shown on the graph at the end of the measuring interval between about $9000 \mathrm{~mm}$ and about $10600 \mathrm{~mm}$, in an area where the machine rarely operates.

The obtained maximum key positioning accuracy results are: bidirectional positioning accuracy $629 \mu \mathrm{m}$, bidirectional positioning repeatability $339 \mu \mathrm{m}$, axis backlash $209 \mu \mathrm{m}$. The deterioration of the positioning results, compared to the previous results, is due to the wear of various machine tool components that affect correct operation during movement.

The demonstrated maximum backlash measured over such a long movement distance and after 8 years of operation is a good result. One of the reasons for this was the second pinion, which was fitted to the machine tool drive.

\section{Conclusions}

The improved rack-and-pinion drive was fitted to a typical production machine tool. The teeth of the toothed rack and both pinions are made with adequate inter-tooth clearance, which has both advantages and disadvantages during operation of the machine.

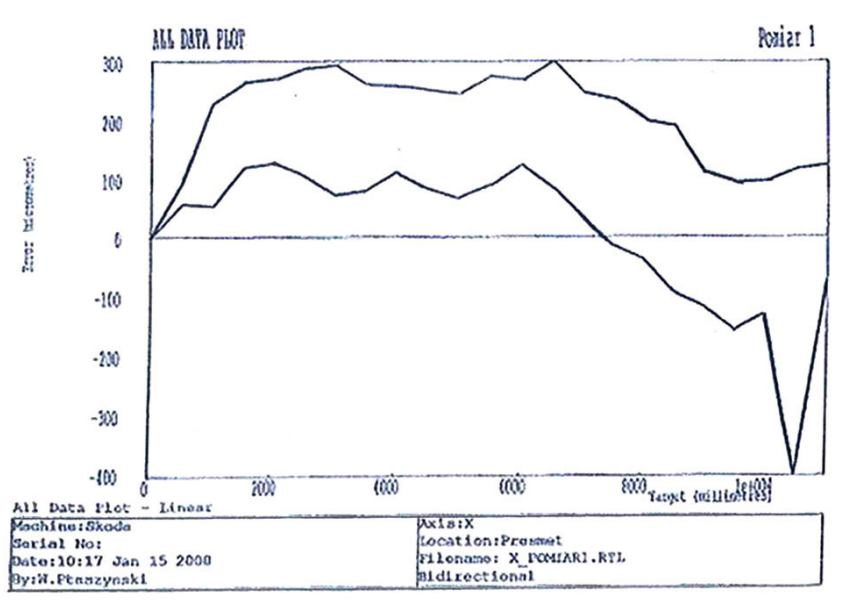

Fig. 10. Diagram of the positioning deviation of a machine tool with only one pinion

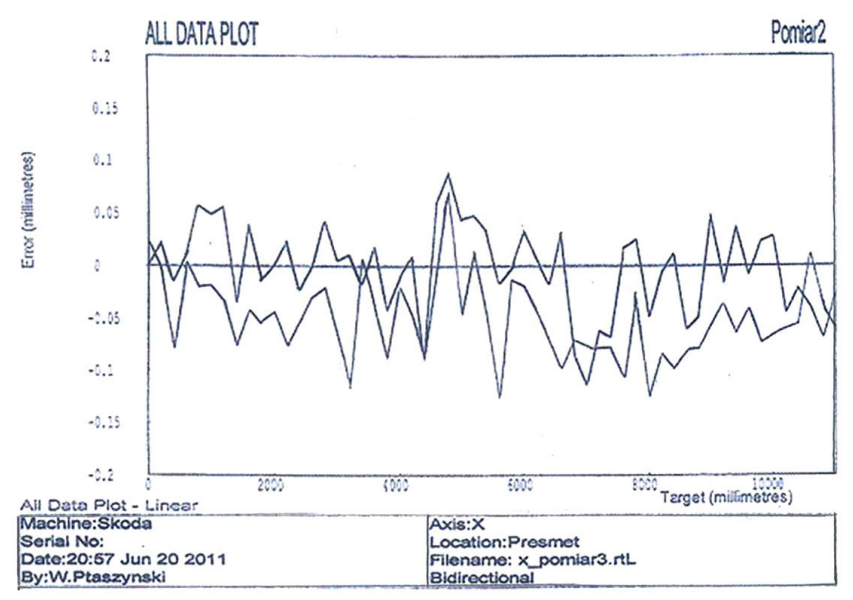

Fig. 11. Diagram of the positioning deviation of a machine tool with a two pinion drive

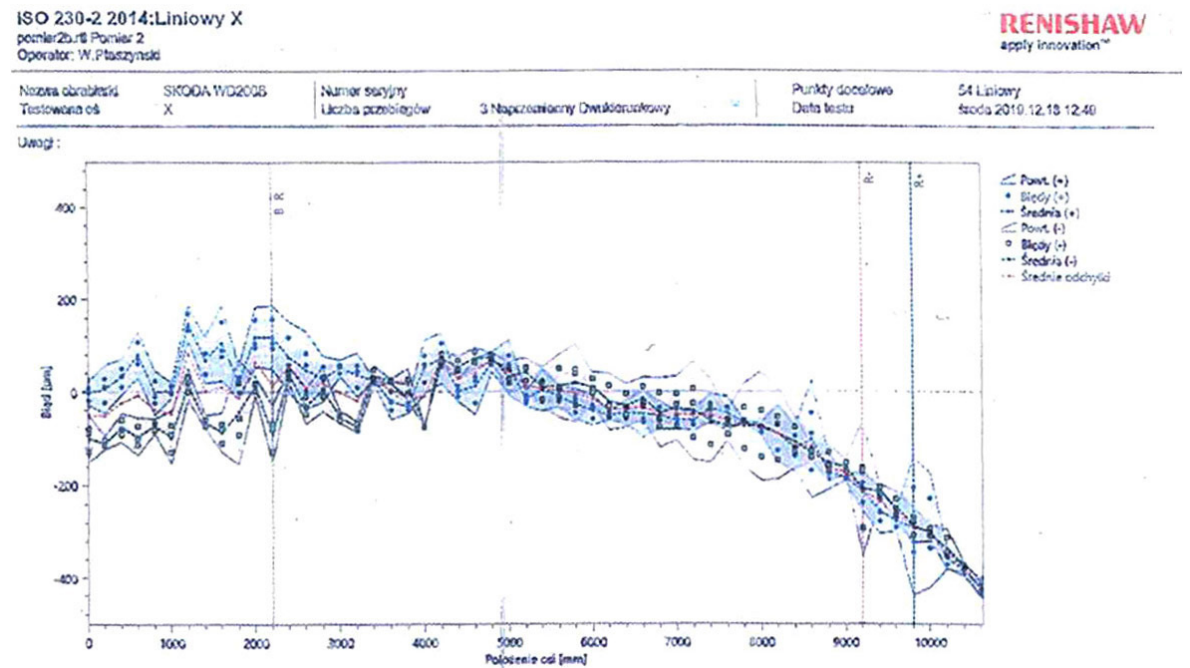

Fig. 12. Diagram of the positioning deviation of a machine tool with a two pinion drive according to ISO-230 
Eliminating backlash is advisable, as the measured results show it significantly improves the positioning of the machine tool. The measure of the clearance between the teeth is the measured backlash.

In machine tools which do not have a second pinion in the drive, the backlash is equal to the inter-tooth clearance, which increases with the operation of the machine tool.

The effectiveness of the use of two-pinion drive in the case shown above is demonstrated by the fact that after approx. 8 years of machine operation, the maximum recorded backlash was $0.209 \mathrm{~mm}$, which is less than the mean backlash of $0.254 \mathrm{~mm}$ recommended by the milling machine manufacturer for the original drive with one pinion.

Good positioning results of a machine tool are influenced by many other factors in addition to the twin pinion drive, including: wear of mating parts, surface condition of bed guides, lubrication of guides, conditions in which the machine tool is operated.

Therefore, installing an improved rack and pinion drive in different machine tools will also give different positioning results. It can be concluded that in any case this improved drive will significantly improve the positioning results.

The presented design solution for an improved rack-and-pinion drive cannot be regarded as the only option.

This solution does not require a large investment for its implementation and can be recommended for dissemination.

\section{References}

Ochęduszko, K. (1985). Kota zębate. Warszawa: WNT.

Poradnik Inżyniera Mechanika (1968). Warszawa: WNT.

Kacalak, W., Ziółkowski, S., Ryckiewicz, J. (1990). Przekładnia ślimakowa z regulowanym luzem międzyzębnym. Patent no. 288 495/1990.

Paderewski, K. (1993). Obrabiarki. Warszawa: WSiP.

Kunstetter, S. (1969). Narzędzia skrawające do metali. Warszawa: WNT.

Kaczmarek, J. (1970). Obróbka wiórowa, ścierna i erozyjna. Warszawa: WNT.

Balul, M.W. i in. (1974). Obrabiarki do skrawania metali. Warszawa: WNT.

Żebrowski, H. (2004). Techniki wytwarzania - obróbka wiórowa, ścierna, erozyjna. Wroctaw: Wydawnictwo Politechniki Wroctawskiej.

Typowe elementy hydrauliki sitowej (1980). Warszawa: Katalog Wydawnictwa Przemystu Maszynowego.

Łożyska toczne (1989). Warszawa: Katalog Wydawnictwa Przemysłu Maszynowego. 